\title{
Investigating the Effect of Pressing Temperature on the Thermal, Mechanical, and Morphological Properties of Nanocomposites Made from Recycled Polyethylene, Nanosilica, and Wood Flour
}

\begin{abstract}
Amir Lashghari ${ }^{a}$ and Ehsan Ganjavi ${ }^{\text {b,* }}$
This study investigated the effect of pressurized temperature on the thermal, mechanical, and morphological properties of nanocomposites made from recycled polyethylene with the weight ratio of $50 \%$. Nanosilica was applied at 3 levels $(0,4,8 \%)$ and wood flour had a weight ratio of $50 \%$. High-density polyethylene (HDPE) went through multiple procedures. It was found that by increasing the nanosilica content, the tensile and flexural strength properties, the residual ash content, and the thermal stability increased along with a reduction in the tensile and flexural modulus and impact resistance. As the temperature increased, the tensile and flexural strength and modulus and the impact resistance decreased. Scanning electron microscopy (SEM) images revealed that samples with $8 \%$ nanosilica showed different polymerization than the wood flour particles.
\end{abstract}

Keywords: Beech wood flour; Recycled polyethylene; Tensile strength and modulus; Nanosilica

Contact information: a: Associate professor, Department of Wood and Paper Science and Technology, Karaj Branch, Islamic Azad University, Karaj, Iran; b: Department of Wood and Paper Science and Technology, College of Agriculture and Natural Resources, Karaj Branch, Islamic Azad University, Karaj, Iran;

* Corresponding author: Ehsanganjavi@gmail.com

\section{INTRODUCTION}

In recent decades, the multilayer plastic wood industry has grown significantly due to its unique characteristics, such as resistance to weathering and low maintenance requirements compared to wood (Shahi et al. 2012). Heat-treated polymers are used to incorporate wood into a polymer matrix in which the lignocellulose materials serve as reinforcements. Every day, a significant amount of plastic waste pollutes the environment. The recycling of this plastic waste is of great economic and environmental importance. In general, polyethylene, polypropylene, polyethylene terephthalate, polystyrene, and polyvinyl chloride (PVC) are the main components of plastics in solid urban waste (Najafi 2013). One way to recycle plastics is to use them to make multi-purpose wood-plastic composites, and many studies have examined the construction of a multi-purpose woodplastic recycled polymer material that focuses more on polyethylene, polypropylene, and PVC (Najafi 2013). Polyethylene is one polymer that can be used to manufacture woodplastic composites due to its suitable melting point (Klyosov 2007).

Adding natural fibers and particles as a reinforcer to the thermoplastic polymers has been shown to improve mechanical properties, such as stiffness (Fu et al. 2002). Natural fibers are advantageous to use due to their low density, renewability, high recyclability, degradability, and most importantly, low cost (Ku et al. 2011). The distribution of the lignocellulosic material, the quantity and type of additives, the quality 
of the joint, the characteristics of the components, the type of equipment, and the conditions of the process affect the multilayer properties of plastic wood (Godard et al. 2009). The largest issue when combining natural fibers with plastics is the incompatibility between the polymer hydrophobicity and the hydrophilicity of the fibers, which can cause poor adhesion and reduce the matrix's ability to transfer stress to the fibers (Selke and Wichman 2004). The adhesion can be enhanced by the addition of a compatibilizing agent. Maleic anhydride is one of the adaptive agents that can be used in conjunction with polyethylene (Harper and Wolcott 2004). There have been recent innovations in nanoparticle technology to strengthen multi-structures. Nanosilica is a promising nanoparticle, due to its spherical and porous structure, high contact surface area, and mineral nature, which can improve the polymeric properties of polymers like polystyrene (Xanthos 2010). Nanopolymers, such as nanosilica, have many industrial applications (Wu et al. 2005). Nanosilica is a promising material due to its hardness and high strength. In addition, silica is a relatively inexpensive material that is chemically inert, heat-resistant, and environmentally friendly (de Dios and Díaz-García 2010). Compared to pure polymers, polymer-silica nanostructures have different physical and mechanical properties, including higher strength characteristics (Du et al. 2012). Researchers believe that silica nanoparticles can improve the strength, hardness, modulus, crystallinity, and melt viscosity properties in polypropylene (Guyard et al. 2006). Much research has been done on the application of silica particles in the form of mixtures with various polymers (Chung et al. 2002; Zhang et al. 2003; Xu et al. 2008; Zhang et al. 2008), but few of them are related to wood-plastic materials. Researchers have found that silica particles can improve the strength, hardness, modulus, crystallization, viscosity, creep resistance, and intrinsic adhesion of polyethylene, polypropylene, and thermoplastic elastomers due to the surface properties of nanosilica particles (Zhang et al. 2003; Rong et al. 2004; Guyard et al. 2006; Parvinzadeh et al. 2010). Various devices have been used to make plastic-wood multilayers (Bledzki et al. 2005), one of which is injection molding, of which there has been little research on the effect of pressurized cylinder temperature on thermal and mechanical properties. Therefore, this study is aimed to investigate the effect of the injection pressure temperature and the nanosilica content on the mechanical, thermal, refractory, and morphological behavior of composites comprising wood flour and recycled polyethylene.

\section{EXPERIMENTAL}

\section{Materials}

\section{Lignocellulose}

Beech wood flour was used as a powder enhancer in the polymer matrix. The beech wood flour was meshed to uniformly measure the size of the particles and reach the desired size with a laboratory sieve. The wood flour was passed through a 60-mesh sieve followed by an 80 -mesh sieve. The sieved flour was oven-dried to reach $1 \%$ moisture content.

\section{Polyethylene}

As the disposable container retailers in Iran are usually unaware of the components of waste containers and the possible presence of impurities in their constituents, municipal solid waste is not systematically separated. Therefore, in an effort to avoid error and increase accuracy, it was decided to prepare matrix materials (recycled polyethylene) in the laboratory instead of collecting used milk bottles. The high-density polyethylene 
(HDPE) was supplied by the Shazand Petrochemical Company (Arak, Iran). The product name for the polymer was HD52518. It had a melt index of $18 \mathrm{~g} / 10 \mathrm{~min}$ and a density of $959 \mathrm{~g} / \mathrm{cm}^{3}$.

\section{Plastic recycling}

To simulate the effect of recycling, the HDPE was subjected to two stages of thermomechanical degradation using a twin-screw extruder (Brabender, Duisburg, Germany). After each extrusion, the output materials were shredded and were converted to granules. The HDPE molten flow index was measured according to the ASTM standard D1238-98 (1998) using a melt index machine (MI-4; Gottfer, Buchen, Germany).

\section{Compatibilizer}

Polyethylene-g-maleic anhydride (PE-g-MA, i.e. MAPE) produced by the Krangin Company (Karaj, Iran) was used in order to make the wood flour and the polymer matrix compatible. The MAPE had a melt flow index of $7 \mathrm{~g} / 10 \mathrm{~min}$ and a density of $0.965 \mathrm{~g} / \mathrm{cm}^{3}$.

\section{Nanosilica}

The nanosilica powder was obtained from Degussa Goldhandel GmbH (Frankfurt, Germany). The specifications of the nanosilica are provided in Table 1.

Table 1. The Nanosilica Profile

\begin{tabular}{|c|c|}
\hline Property & Specification \\
\hline Silicon Oxide & $\mathrm{SiO}_{2}$ \\
\hline Purity & $99+\%$ \\
\hline Average Particle Size (APS) (nm) & 11 to $13 \mathrm{~nm}$ \\
\hline Specific Surface Area (SSA) & $200 \mathrm{~m}^{2} / \mathrm{g}$ \\
\hline Bulk Density & $<0.10 \mathrm{~g} / \mathrm{cm}^{3}$ \\
\hline Color & White \\
\hline Moisture & $<2 \%$ \\
\hline Weight Loss on Ignition & $30 \%$ \\
\hline Certificate of Analysis & Specification \\
\hline $\mathrm{SiO} 2$ & $<99 \%$ \\
\hline $\mathrm{Ti}$ & $<120 \mathrm{ppm}$ \\
\hline $\mathrm{Ca}$ & $<70 \mathrm{ppm}$ \\
\hline $\mathrm{Na}$ & $<50 \mathrm{ppm}$ \\
\hline $\mathrm{Fe}$ & $<20 \mathrm{ppm}$ \\
\hline *Note: According to the producer information & \\
\hline
\end{tabular}

\section{Methods}

\section{Mixing materials}

The recycled HDPE, beech wood flour, MAPE, and nanosilica were combined in an extruder (COLLIN Lab \& Pilot Solutions, Maitenbeth, Germany). The compositions of each treatment are shown in Table 2. After the mixing process, the samples were ground to prepare granules using a pilot-scale grinder (WG-LS 200; WIESER, Bayern, Germany). 
Table 2. Weight Percentage of the Components from Different Compositions of the Multilayer Plastic Wood Treatments

\begin{tabular}{|c|c|c|c|c|}
\hline $\begin{array}{c}\text { Pressure } \\
\text { Temperature }\left({ }^{\circ} \mathrm{C}\right)\end{array}$ & Nanosilica (\%) & MAPE (\%) ${ }^{* *}$ & rHDPE (\%) & Wood Flour (\%) \\
\hline \multirow{3}{*}{170} & 0 & 3 & 50 & 50 \\
\cline { 2 - 5 } & 4 & 3 & 50 & 50 \\
\cline { 2 - 5 } & 8 & 3 & 50 & 50 \\
\cline { 2 - 5 } & 0 & 3 & 50 & 50 \\
\cline { 2 - 5 } & 4 & 3 & 50 & 50 \\
\cline { 2 - 5 } & 8 & 3 & 50 & 50 \\
\hline \multirow{2}{*}{$\begin{array}{l}* \text { Based on the total weight of several structures } \\
* \text { Based on the total weight of the polymer }\end{array}$}
\end{tabular}

\section{Preparation of samples}

To prepare the samples, the granules obtained from each compound were dried for $24 \mathrm{~h}$ in an oven at $80^{\circ} \mathrm{C}$. Then, a pilot-scale injection molding machine (MPC-40; Aslanian Machine Company, Tehran, Iran) developed the test specimens at cylinder temperatures of $170{ }^{\circ} \mathrm{C}$ and $190{ }^{\circ} \mathrm{C}$ for the tensile, flexural, and impact tests. Prior to the mechanical tests, the samples were conditioned for two weeks at $20{ }^{\circ} \mathrm{C} \pm 2{ }^{\circ} \mathrm{C}$ and $65 \% \pm 5 \%$ relative humidity. The ASTM D638-10 (2010) for the tensile (dimensions of the standard dumbbell (dog-bone) samples were 145 x 10 x 4 mm (length $\mathrm{x}$ width $\mathrm{x}$ thickness)), ASTM D790-10 (2010) for flexural (dimensions of the specimens were $105 \times 13$ x 5 mm (length $\mathrm{x}$ width $\mathrm{x}$ thickness)), and ASTM D256-10 (2010) for impact (dimensions of the specimens were 60 x 12 x 6 mm (length x width $\mathrm{x}$ thickness)), were used respectively. For each treatment level, four replications were measured for each property and average values were reported.

\section{$X$-ray diffraction test}

The distribution of the nanoparticles in the polymer matrix was investigated using X-ray diffractograms from a Philips diffractometer (Amsterdam, Netherlands). The diffractometer was used in the range of angles $2 \theta=20^{\circ}$ to $80^{\circ}$. The current of the device was $30 \mathrm{~mA}$, its voltage was $40 \mathrm{kV}$, its step was $0.02^{\circ} \mathrm{C}$, and its speed was $0.3^{\circ} \mathrm{C} / \mathrm{s}$. In this device, a cobalt atomic beam with a wavelength of $\lambda=1.79^{\circ} \mathrm{A}$ was used as a detector.

\section{Scanning electron microscopy (SEM)}

An AIS2100scanning electron microscope made by the Seron Technology Company (Gyeonggi-do, Korea) was used to assess the samples.

Thermogravimetric Analysis (TGA) test

The TGA measurements were performed using a thermal analyzer (TGA Q50; PL150, Agilent Technologies, Santa Clara, CA, USA), a $7 \mathrm{mg}$ sample was measured within a temperature range of 25 to $700{ }^{\circ} \mathrm{C}$ with a heat rate of $15{ }^{\circ} \mathrm{C} / \mathrm{min}$.

\section{Statistical analysis}

The results from the mechanical tests were analyzed by a completely randomized statistical design under the factorial test, using SPSS software (IBM, Armonk, USA). The Duncan multi-domain test was used at the $95 \%$ confidence level to compare the means. 


\section{RESULTS AND DISCUSSION}

\section{Melted Flow Index}

The melt flow index indicates the degree of polymer fluidity. Changes in the melt flow index indicate changes in the polymer structure. The results showed that the HDPE molten flow index decreased from $18 \mathrm{~g} / 10 \mathrm{~min}$ for the virgin polymer to $17.75(0.06) \mathrm{g} / 10$ min after the material was recycled twice. The increase in viscosity during the recycling process is probably due to branching or cross-linking. In general, the destruction mechanism in the HDPE specimens includes branching, cross-linking, and main chain failure (Zahavich et al. 1997; Pinheiro et al. 2004). Similar results have been reported in HDPE by other researchers (Mendes et al. 2011).

The effect of nanosilica and press temperature on the mechanical properties of polymers

The results from the analysis of variance (ANOVA) tests of the independent and interaction effect of nanosilica and the press temperature on the modulus and tensile strength, the modulus and flexural strength, and the shock-free impact resistance, are shown in Table 3. According to Table 3, the effect of nanosilica on the tensile strength, flexural strength, and impact resistance is significant, but not significant on other studied features. In addition, the effect of the press temperature was significant on just tensile strength and not in other features. In contrast, the interaction of the nanosilica and the pressing temperature on any of the resistive properties was not significant.

Table 3. ANOVA Test Results for the Studied Factors and the F-value

\begin{tabular}{|c|c|c|c|c|c|}
\hline & \multicolumn{2}{|c|}{ Tension (MPa) } & \multicolumn{2}{|c|}{ Flexural (MPa) } & \multirow{2}{*}{$\begin{array}{c}\text { Impact Strength } \\
\left(\mathrm{KJ} / \mathrm{m}^{2}\right)\end{array}$} \\
\hline & Strength & Modulus & Strength & Modulus & \\
\hline The Effect of Nanosilica & $57.143^{\star \star}$ & $3.121 \mathrm{~ns}$ & $40.360^{\star *}$ & $2.816 \mathrm{~ns}$ & $61.084^{\star \star}$ \\
\hline $\begin{array}{l}\text { The Effect of Pressure } \\
\text { Temperature }\end{array}$ & $83.419^{\star *}$ & $0.010 \mathrm{~ns}$ & $0.720 \mathrm{~ns}$ & $1.862 \mathrm{~ns}$ & $0.268 \mathrm{~ns}$ \\
\hline $\begin{array}{l}\text { The Effect of Nanosilica } \\
\text { and Press Temperature }\end{array}$ & $1.892 \mathrm{~ns}$ & $2.537 \mathrm{~ns}$ & $0.0988 \mathrm{~ns}$ & $3.321 \mathrm{~ns}$ & $0.079 \mathrm{~ns}$ \\
\hline
\end{tabular}

Figures 1 to 5 show the effects of nanosilica and the press temperature on the mechanical properties of the nanostructures. After investigating the effect of nanosilica on the mechanical properties of recycled polyethylene nanoparticles and beech wood flour, several results were obtained. First, the tensile and flexural strength increased linearly with higher addition levels of nanosilica. This increase in strength can be attributed to the fact that nanosilica increases the tension between flour and the matrix by withstanding stress (Ramos et al. 2005). In addition, silica nanoparticles act as a nucleating agent in crystal growth, so as the nanoparticles enter, the number of crystals increases (Tian et al. 2006). The tensile and flexural modulus decreased as the nanosilica content increased. This is likely because the high surface energy of the silica nanoparticles causes them to absorb each other due to the presence of the hydroxyl hydrophilic groups and the silica gravitational forces. Therefore, the reduction in the tensile and flexural modulus due to the increased nanosilica content is attributed to the accumulation of nanoparticles, their nonuniform distribution, and the phenomenon of particle chlorination in the multilayer bed (Yang and Gu 2007). 
$\square 170 \quad$ II 190

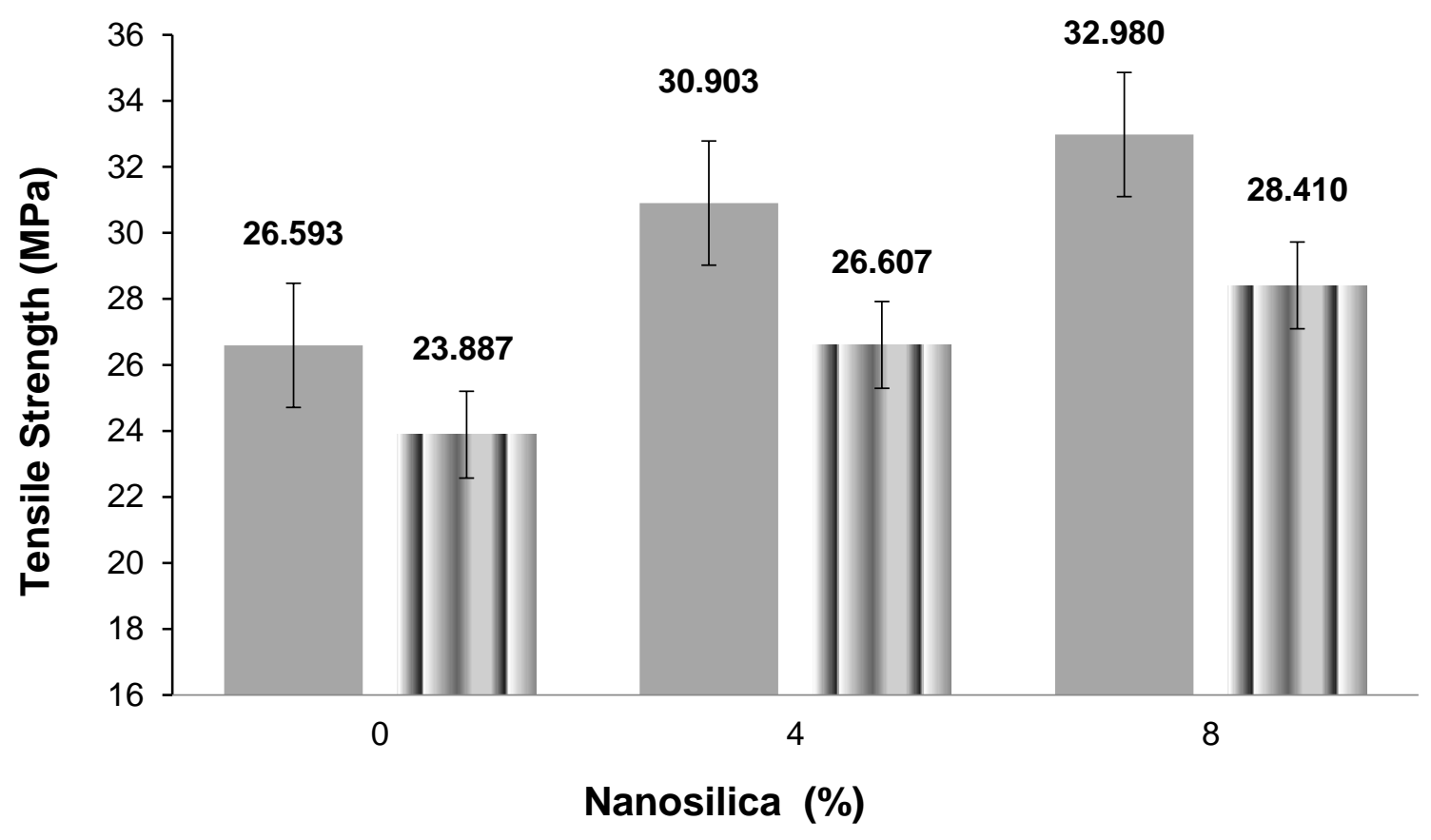

Fig. 1. The interaction of nanosilica and pressing temperature on the tensile strength

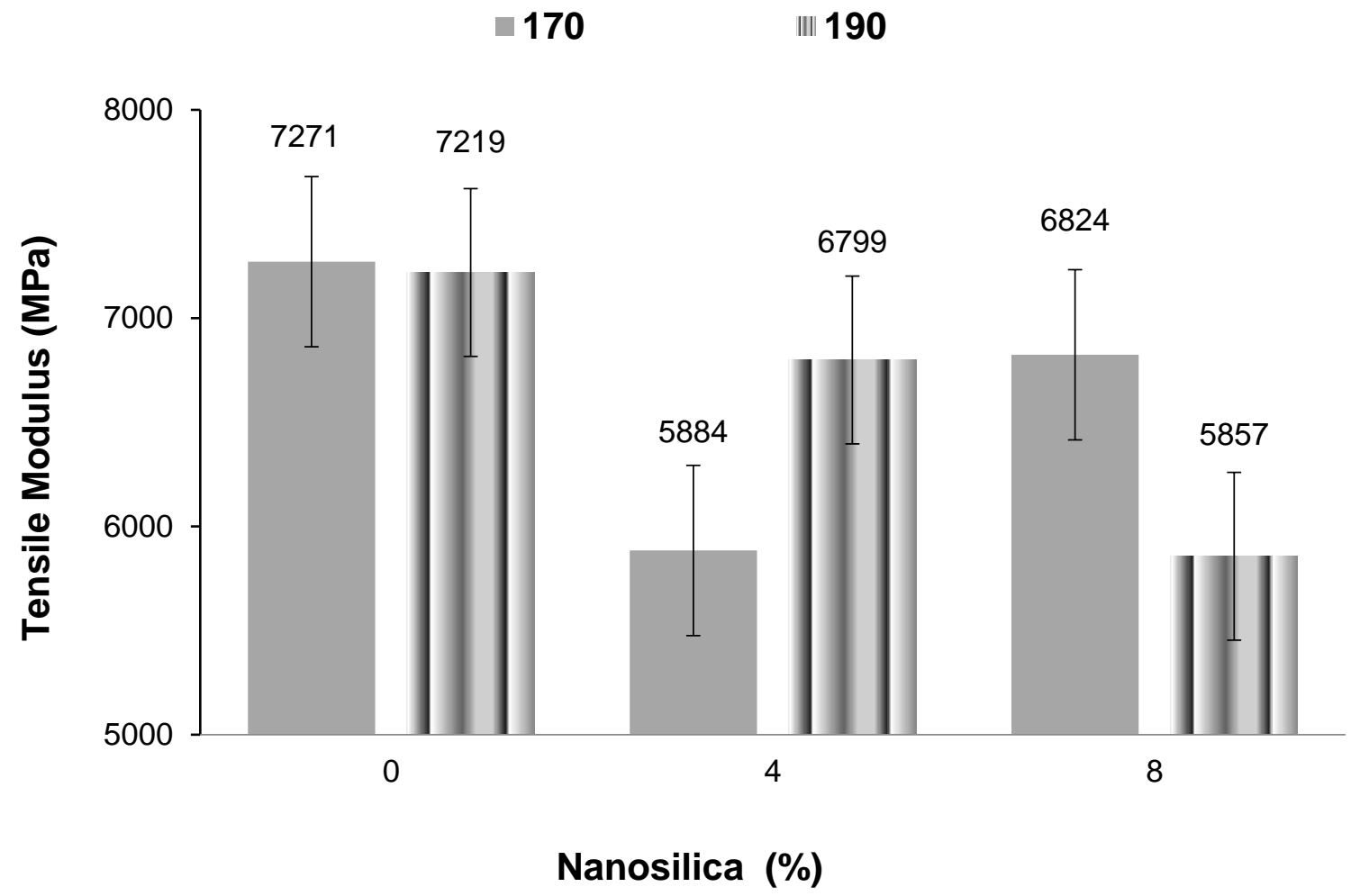

Fig. 2. The interaction of nanosilica and pressing temperature on the tensile modulus 
$\square 170 \quad$ 띠 190

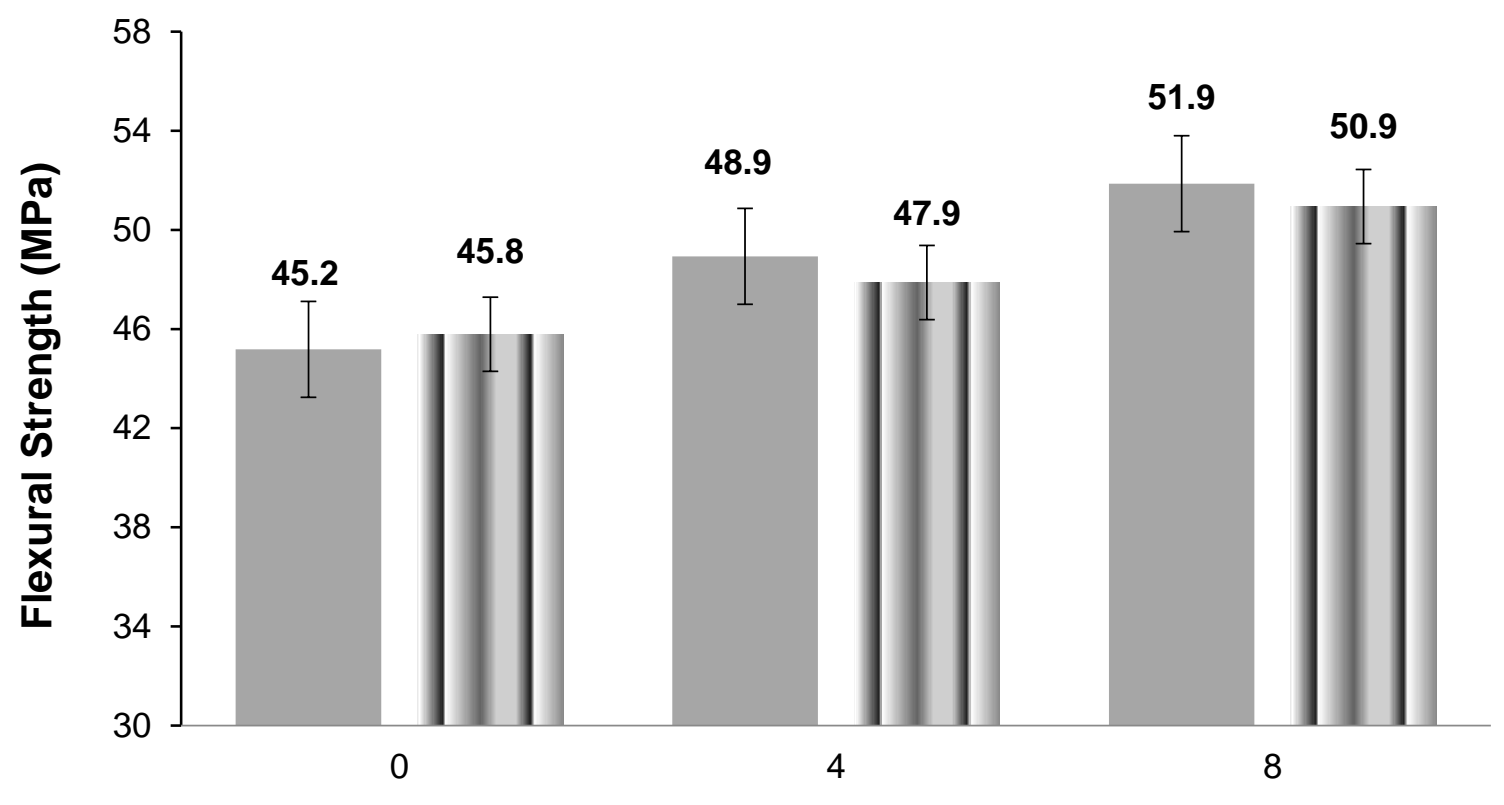

Nanosilica (\%)

Fig. 3. The interaction of nanosilica and pressing temperature on the flexural strength

$$
\square 170 \quad \text { 피 } 190
$$

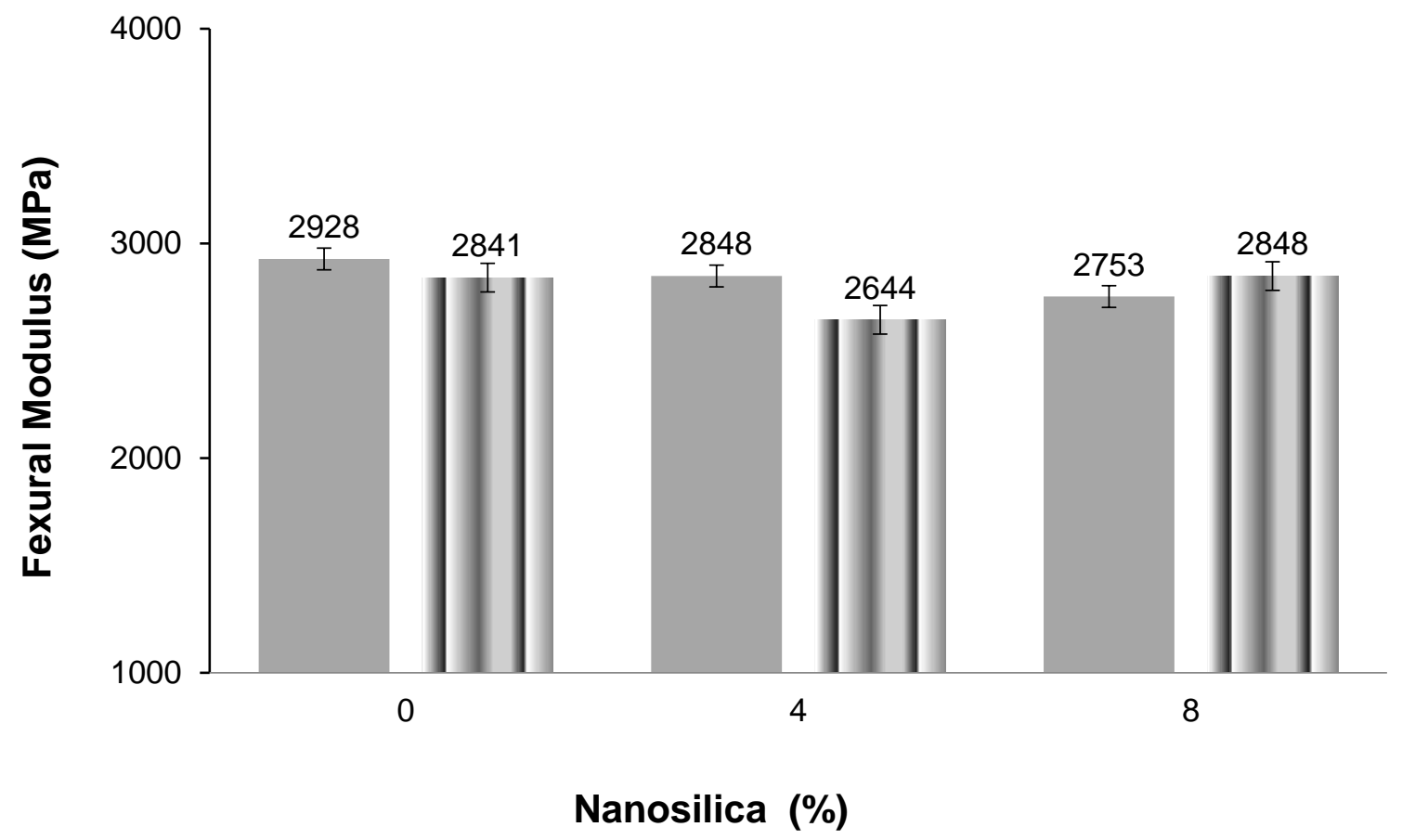

Fig. 4. The interaction of nanosilica and pressing temperature on the flexural modulus 
$\square \mathbf{1 7 0} \quad$ 피 190

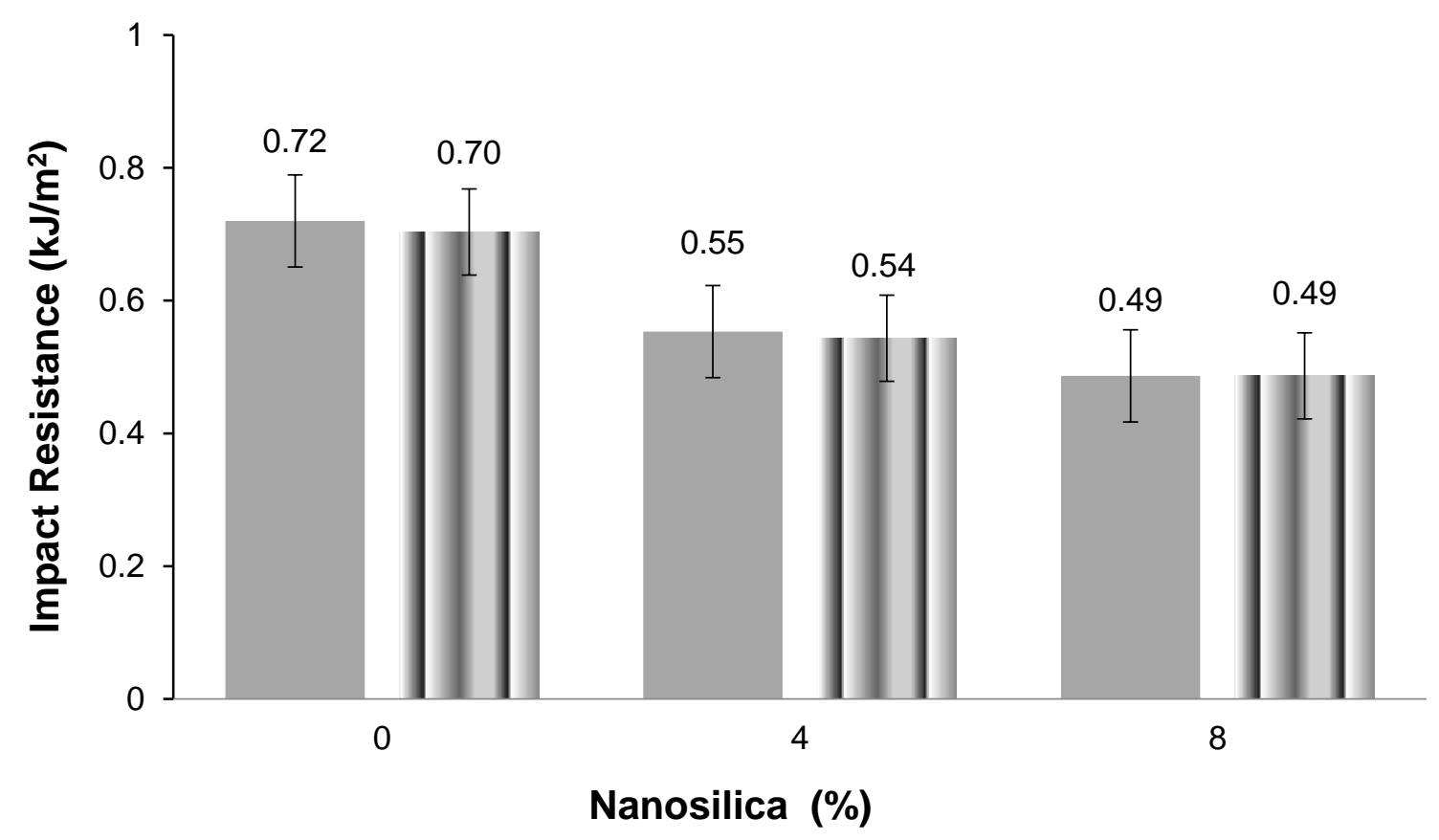

Fig. 5. The interaction of nanosilica and pressing temperature on the impact resistance

Another factor in the reduction of strength properties is the reduction in the polymerizing properties of the polymers due to the use of high amounts of nanosilica, which can cause improper bonding of the lignocellulose and the matrix fibers (Deka and Maji 2013).

It was observed that when the nanosilica content was increased, the impact resistance of the multi-dimensional plastic wood bearing decreased. This is likely because hard fillers generally reduce the impact strength. In hard and brittle polymers, cracks grow easily, so the particles act as a crack initiator and reduce the impact resistance. The reduction in the impact resistance was predictable due to the addition of the nanosilica, as its presence makes multi-structures more brittle and reduces their impact resistance. The presence of nanomaterials in the polymer matrix reduces the mobility of the chains, reduces the possibility of wasting their energy, increases the energy absorbed by the polymer, and creates stress points. The stress points can be the starting point for failure (Han et al. 2008). In most cases, the impact resistance is determined by the polymer extruding from the filler surface and the amount of fine cracking. Hard and flexible polymers can be made into chunks by adding hard particles from which the polymer has been removed. When this occurs, the micro-crack energy is increased, and a large volume fraction of the sample is impacted. While this can increase the toughness of the samples, it consumed more energy during preparation (Hemmasi et al. 2013).

A higher nanomaterial content will cause reduction in impact strength (MartinGallego et al. 2011). This relationship can be impacted by the accumulation of nanomaterials, which can lead to the creation of multiple concentrations and stresses on the background material. In fact, this leads to the development of large cracks and a reduced impact strength. Therefore, the addition of high percentages of nanosilica did not allow the 
absorption of energy into the matrix, which led to the crushing of the samples with higher amounts of the nanographs (Rafiee et al. 2009). The stresses in the joint between the nanosilica and the ground material can cause the separation of the reinforcing phase from the background phase. This can cause the formation of cavities that will lead to multiple cracks (Rafiee et al. 2009).

At $170{ }^{\circ} \mathrm{C}$, the heat transfer and the adhesion improved. However, at $190{ }^{\circ} \mathrm{C}$, the adhesion characteristics and the quality of the polymer surface decreased and the tensile and the flexural resistance decreased. Increasing the flexural modulus defines the change in the form of compound material under the load, which is a positive factor in engineering structures that have to endure a large load without changing shape.

Table 2 represents that the tensile strength of the polystructures constructed at 170 ${ }^{\circ} \mathrm{C}$ was approximately $14 \%$ higher than the tensile strength of the structures constructed at $190{ }^{\circ} \mathrm{C}$. At $170{ }^{\circ} \mathrm{C}$, the heat transfer and the adhesion improved; However, at $190{ }^{\circ} \mathrm{C}$, the adhesion characteristics and the quality of the polymer surface decreased and the tensile and the flexural resistance decreased. Increasing the flexural modulus defines the change in the form of compound material under the load, which is a positive factor in engineering structures that have to endure a large load without changing shape.

The highest resistance, tensile modulus, flexural modulus, and flexural resistance were obtained in the composite formed at $170{ }^{\circ} \mathrm{C}$. The increased resistance can be attributed to the uniform dispersion and distribution of the filler inside the polymer field, which increased the interaction between the filler and the polymer matrix. As expected, the mechanical properties improved due to the uniform distribution of the filler in the polymer field (Andrews et al. 2002; Jose et al. 2007).

Between the flour and the polymer, a strong adhesion is required to improve the mechanical properties of the composites. The final composite properties depend on the construction conditions such as mixing at the proper temperature to achieve the optimal dispersion of the composite properties (Bledzki et al. 2005). The reduced mechanical properties at $190{ }^{\circ} \mathrm{C}$ can be due to the formation of acidic chemicals such as acetic acid and formic acid, which cause hemicellulosic decomposition (Garrote et al. 2001). The decomposition of the long-chain cellulosic acids to short-chains acids causes cellulose dissolution. In addition, the carbon-carbon and carbon-oxygen connections are lost at the polymer level as the temperature increases. This causes the isolation of the lignin, hemicellulose, and cellulose copolymer system (Çolak et al. 2007). The shortening of the cellulose chain affects the resistance properties (Rowell 2012).

\section{The TGA Analysis}

The TGA is a suitable tool to determine the sustainability of the composite in temperature conditions and the process of thermal decomposition. The effect of the nanosilica content on the weight loss of the polyethylene/flour composite at the $50 \%$ level, during the heating time (from $25{ }^{\circ} \mathrm{C}$ to $700{ }^{\circ} \mathrm{C}$ ), is shown in Table 4 . This table shows the temperature of degradation in different percentage weight loss and residual weight at 600

${ }^{\circ} \mathrm{C}$ for nanoparticles of plastic wood. The addition of the nanosilica also sped up the first stage of destruction and produced more coal. 
Table 4. Temperature Required to Reach Different Percentages of Weight Loss for the Nanosilica Composite Samples

\begin{tabular}{|c|c|c|c|c|c|c|c|c|c|}
\hline & & \multicolumn{8}{|c|}{$\%$ Weight Loss of Sample } \\
\hline Temperature & Sample & $5 \%$ & $10 \%$ & $20 \%$ & $40 \%$ & $60 \%$ & $80 \%$ & $90 \%$ & $\begin{array}{c}\text { The } \\
\text { Remaining } \\
\text { Weight at } \\
600^{\circ} \mathrm{C}\end{array}$ \\
\hline \multirow[t]{3}{*}{$170^{\circ} \mathrm{C}$} & $0 \%$ Nanosilica & 287 & 319 & 354 & 445 & 473 & 489 & 550 & 8.7 \\
\hline & 4\% Nanosilica & 288 & 315 & 355 & 458 & 479 & 492 & 511 & 8.9 \\
\hline & $8 \%$ Nanosilica & 289 & 319 & 362 & 462 & 481 & 494 & 668 & 10.5 \\
\hline \multirow[t]{3}{*}{$190^{\circ} \mathrm{C}$} & $0 \%$ Nanosilica & 289 & 319 & 359 & 460 & 479 & 491 & 504 & 8.4 \\
\hline & 4\% Nanosilica & 289 & 319 & 360 & 461 & 480 & 492 & 505 & 8.4 \\
\hline & 8\% Nanosilica & 292 & 322 & 363 & 462 & 480 & 494 & - & 11.9 \\
\hline
\end{tabular}

The thermal stability of the composites is one of the important parameters for the processing and application of these materials. The production of some composites requires mixing fibers and a high temperature matrix. Therefore, the thermal degradation of the lignocellulosic materials causes adverse effects on the composite properties.

Of the main chemical components, hemicellulose has the lowest stability against heat, and its decomposition starts from $225^{\circ} \mathrm{C}$. After hemicellulose, lignin and cellulose begin to decompose (Enayati et al. 2009; Rowell 2012). The initial decomposition of lignin and cellulose begin at approximately $250^{\circ} \mathrm{C}$ and $275{ }^{\circ} \mathrm{C}$, respectively. However, because lignin has a higher resistance to heat, it degrades slower than cellulose with a maximum thermal destruction at $500{ }^{\circ} \mathrm{C}$ (Yang and Gu 2007; Enayati et al. 2009; Rowell 2012). The degradation behavior of lignin is due to the destruction of some relatively weak bonds of alkyl binders attached to aromatic lignin rings at low temperatures. Meanwhile, stronger links in the aromatic circles of lignin are destroyed at higher temperatures, which leads to its high resistance properties (Enayati et al. 2009).

Table 4 shows that $5 \%$ of the weight loss for the $0 \%, 4 \%$, and $8 \%$ nanosilica samples formed at $170{ }^{\circ} \mathrm{C}$ occurred at $287{ }^{\circ} \mathrm{C}, 288^{\circ} \mathrm{C}$, and $289{ }^{\circ} \mathrm{C}$, respectively. The samples with a higher nanosilica content required higher temperatures to achieve the same weight loss of samples with lower amounts of nanosilica. The ash content increased in the samples with higher nanosilica content. The amount of ash remaining at $600{ }^{\circ} \mathrm{C}$ in the $0 \%$, $4 \%$, and $8 \%$ nanosilica samples formed at $170{ }^{\circ} \mathrm{C}$, was $8.7 \%, 8.9 \%$, and $11.9 \%$, respectively. The amount of ash remaining at $600{ }^{\circ} \mathrm{C}$ in the $0 \%, 4 \%$, and $8 \%$ nanosilica samples formed at $190{ }^{\circ} \mathrm{C}$, respectively, was $8.4 \%, 8.4 \%$, and $10.4 \%$.

\section{Morphology}

Structural study via X-ray diffraction test

Figures 6 and 7 show the scattering intensity at an angle of $2 \theta$ for nanosilica powder and the $4 \%$ and $8 \%$ nanosilica composites formed at 170 and $190{ }^{\circ} \mathrm{C}$. The scattering peak for the nanoparticles shows an unformed silica particle equal to $2 \theta=22.07^{\circ}$. The X-ray diffraction analysis was used to evaluate the nanosilica in the polymer field in order to measure the crystalline proportion of nanosilica.

In the nanocomposite samples, the crystallinity was lower in the samples with higher nanosilica content (Figs. 6 and 7). The intensity of the other crystal peaks was also lower. The decrease in the crystal peak intensity can be attributed to the partial 
crystallization of the amorphous part in the composite materials due to the addition of the amorphous silica nanoparticles and wood flour.

The lower peak intensity indicates that the silica particles will become oxidized at a higher nanoparticle content. This can be attributed to the formation of hydrogen bonds among silica particles, due to the increased distance between the layers and their proximity. Deka and Maji (2013) examined the effect of nanosilica on the properties of wood flour and polymer composites and found that the peak intensity decreased as the silica content increased. This showed that nano-silica particles have been injected into plastic wood.

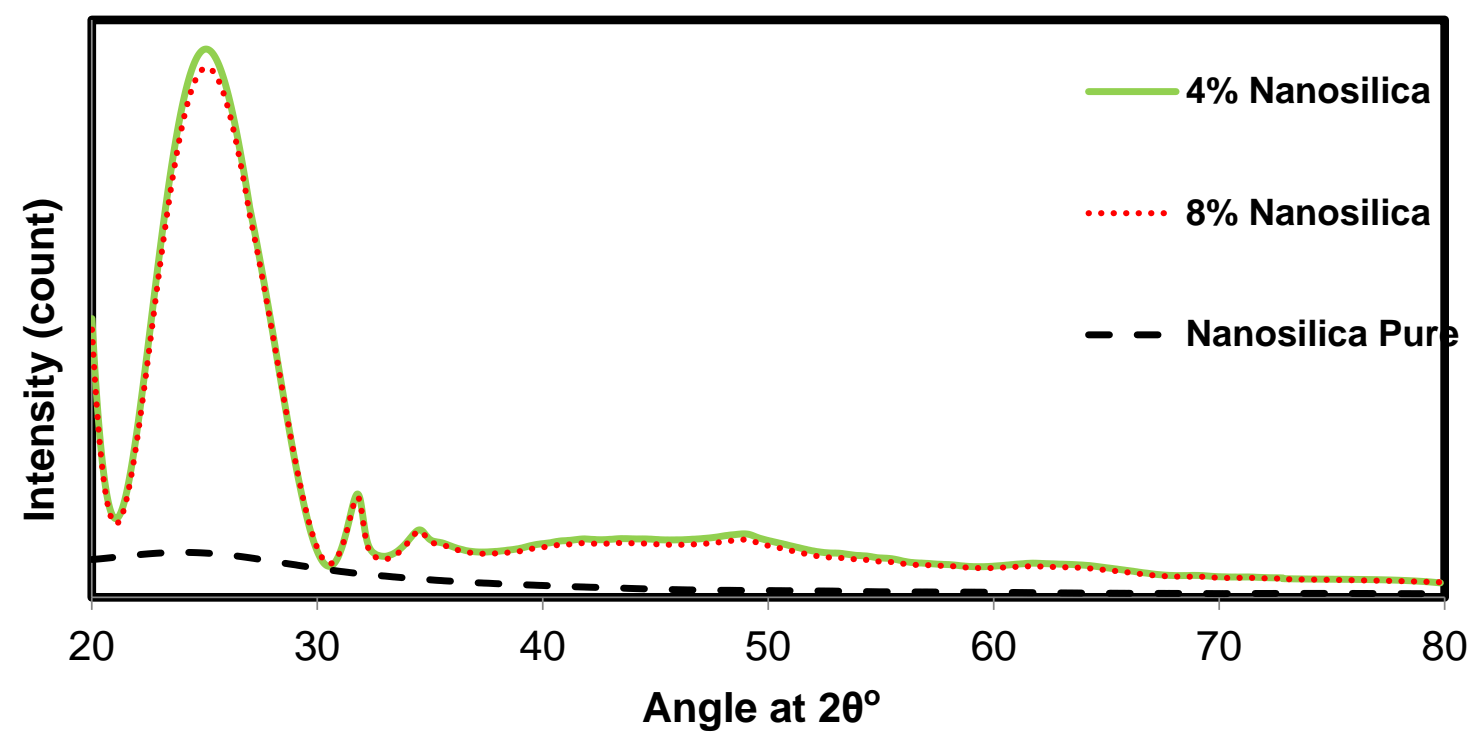

Fig. 6. The multiprupose $X$-ray nanoscale spectrum containing the $4 \%$ nanosilica, $8 \%$ nanosilica, and pure nanosilica samples at $170{ }^{\circ} \mathrm{C}$

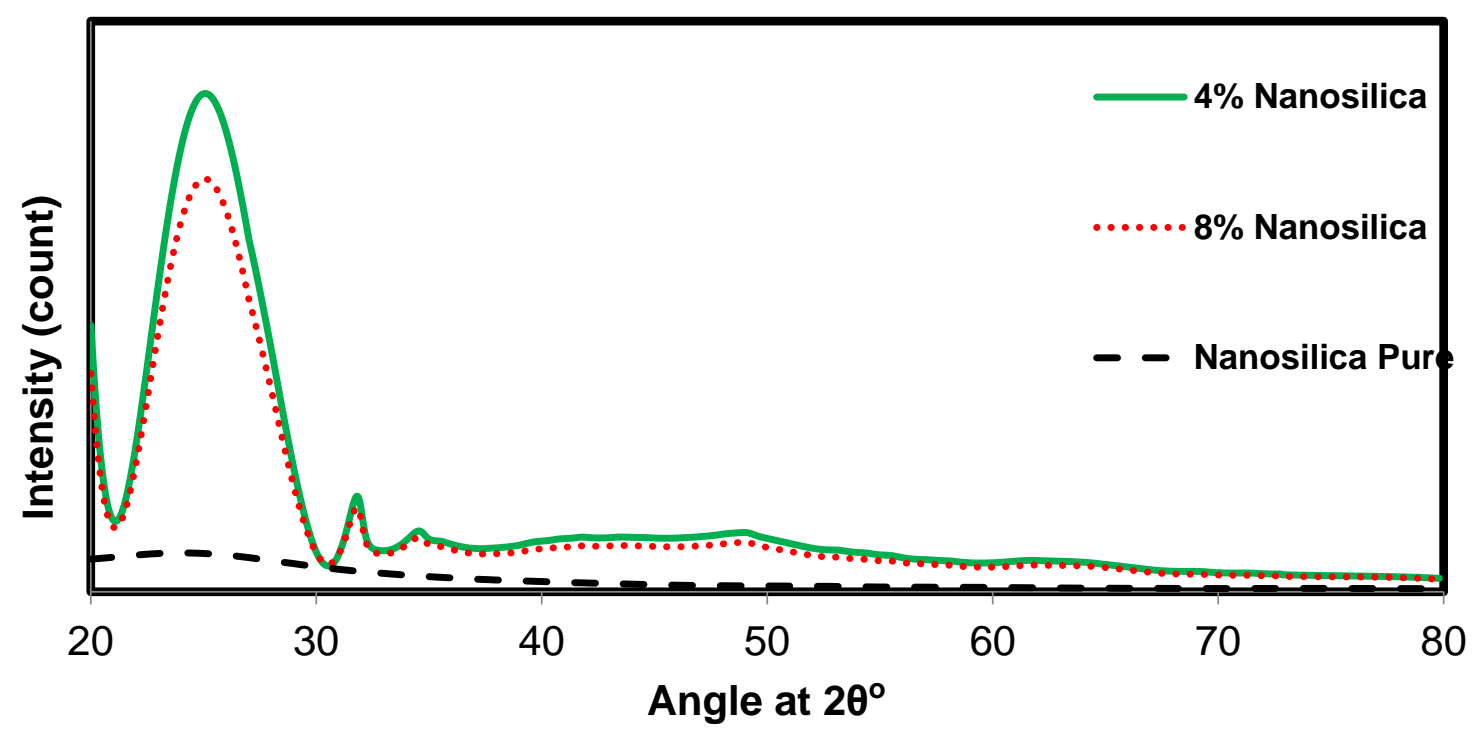

Fig. 7. The multipurpose $X$-ray nanoscale spectrum containing the $4 \%$ nanosilica, $8 \%$ nanosilica, and pure nanosilica samples at $190^{\circ} \mathrm{C}$ 


\section{Morphology Analysis via SEM}

The distribution and compatibilizer between the fillers and the matrices were observed using images obtained from the SEM analysis. Figures 8a, 8b, and 8c show the failure levels of the $170{ }^{\circ} \mathrm{C}$ nanocomposite samples at $0 \%, 4 \%$, and $8 \%$ nanosilica content, respectively. Figures 8d, 8e, and 8f show the failure levels of the $190{ }^{\circ} \mathrm{C}$ nanocomposite samples at $0 \% 4 \%$, and $8 \%$ nanosilica content, respectively. As can be seen in Fig. 8a and Fig. 8d, when the $0 \%$ nanosilica sample was broken, the wood flour particles were safely removed from their place in the background polymer. There are visible gaps around the wood flour particles, which indicates poor interaction within the flour surface. As the nanosilica content was increased to $8 \%$, a strong bond was formed between the wood flour particles and the polymer. In the common surface area, there was greater bonding and fewer surface gaps. The operation of the wood flour particles by polymer is much better and failure of wood flour particles along with polymer failure has occurred.

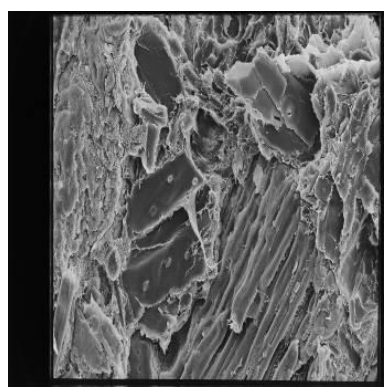

(a)

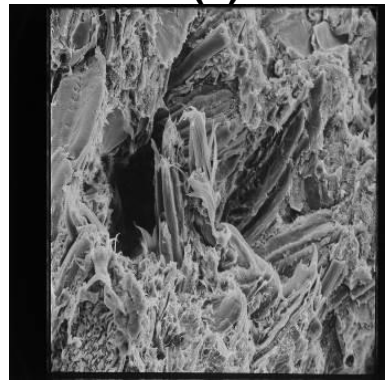

(d)

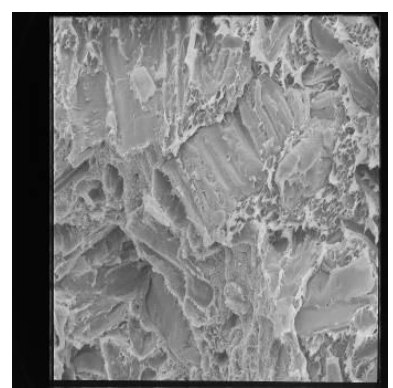

(b)

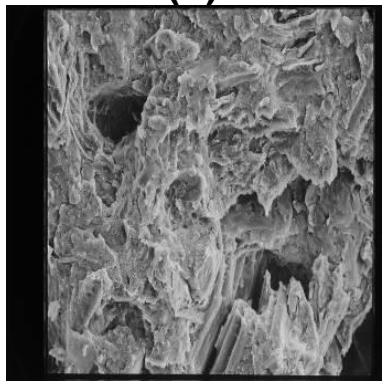

(e)

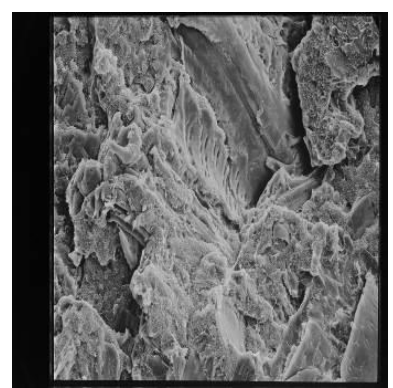

(c)

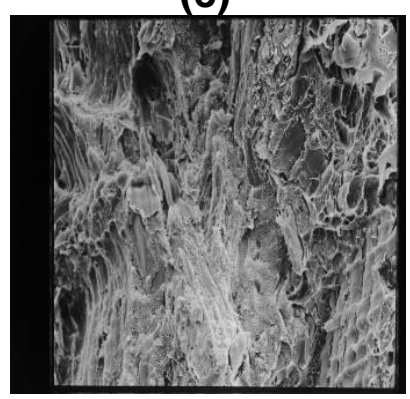

(f)

Fig. 8. The SEM images of a) $0 \%$ nanosilica and $170{ }^{\circ} \mathrm{C}$, b) $4 \%$ nanosilica and $170{ }^{\circ} \mathrm{C}$, c) $8 \%$ nanosilica and $170{ }^{\circ} \mathrm{C}$, d) $0 \%$ nanosilica and $190{ }^{\circ} \mathrm{C}$, e) $4 \%$ nanosilica and $190{ }^{\circ} \mathrm{C}$, and f) $8 \%$ nanosilica and $190^{\circ} \mathrm{C}$

\section{CONCLUSIONS}

1. As the nanosilica content in the composite samples increased, the tensile and flexural strength increased significantly, while the tensile and flexural modulus decreased at insignificant levels.

2. As the nanosilica content increased, the resistance to immovable impact decreased.

3. As the temperature increased, the impact resistance for the tensile and flexural strength and modulus decreased. 
4. With the increase in the nanosilica content, the residual ash content and the thermal stability increased. However, temperature had a negative affect on the residual ash content.

5. The SEM image analysis revealed that the samples with a nanosilica content of $8 \%$ had much better polymerization of the wood flour particles and the failure of the wood flour particles occurred with the polymer failure.

\section{REFERENCES CITED}

Andrews, R., Jacques, D., Minot, M., and Rantell, T. (2002). "Fabrication of carbon multiwall nanotube/polymer composites by shear mixing," Macromolecular Materials and Engineering 287(6), 395-403. DOI: 10.1002/14392054(20020601)287:6<395::AID-MAME395>3.0.CO;2-S

ASTM D256-10 (2010). "Standard test method for determining the izod pendulum impact resistance of plastics," American Society for Testing and Materials, West Conshohocken, PA.

ASTM D638-10 (2010). "Standard test method for tensile properties of plastics," American Society for Testing and Materials, West Conshohocken, PA.

ASTM D790-10 (2010). "Standard test methods for flexural properties of unreinforced and reinforced plastics and electrical insulating materials," American Society for Testing and Materials, West Conshohocken, PA.

ASTM D1238-98 (1998). "Standard test method for melt flow rates of thermoplastics by extrusion plastometer," American Society for Testing and Materials, West Conshohocken, PA.

Bledzki, A. K., Sperber, V. E., Specht, K., Letman, M. A., and Viksne, A. (2005). "Effect of defined waxes and coupling agents on moisture behavior of injection molded woodfiber-reinforced PP composites," in: Proceedings of $8^{\text {th }}$ International Conference on Woodfiber-Plastic Composites (and Other Natural Fibers), Madison, WI.

Chung, S.-C., Hahm, W.-G., Im, S. S., and Oh, S.-G. (2002). "Poly(ethylene terephthalate) (PET) nanocomposites filled with fumed silicas by melt compounding," Macromolecular Research 10(4), 221-229. DOI: 10.1007/BF03218309

Çolak, S., Çolakoğlu, G., and Aydin, I. (2007). "Effects of logs steaming, veneer drying and aging on the mechanical properties of laminated veneer lumber (LVL)," Building and Environment 42(1), 93-98. DOI: 10.1016/j.buildenv.2005.08.008

de Dios, A. S., and Díaz-García, M. E. (2010). "Multifunctional nanoparticles: Analytical prospects," Analytica Chimica Acta 666(1-2), 1-22. DOI: 10.1016/j.aca.2010.03.038

Deka, B. K., and Maji, T. K. (2013). "Effect of $\mathrm{SiO}_{2}$ and nanoclay on the properties of wood polymer nanocomposite," Polymer Bulletin 70(2), 403-417. DOI 10.1007/s00289-012-0799-6

Du, J., Xu, L., Tang, J., and Chen, Y. (2012). "Surface modification of nano-silica and its application in holographic coatings," Advanced Science Letters 10(1), 264-266. DOI: 10.1166/asl.2012.3705

Enayati, A. A., Hosseinaei, O., Wang, S., Mirshokraie, S. A., and Tajvidi, M. (2009). "Thermal properties of wood-plastic composites prepared from hemicellulose- 
extracted wood flour," Iranian Journal of Polymer Science and Technology 22(3), 171-181. DOI: 10.22063/jipst.2013.633

Fu, S.-Y., Xu, G., and Mai, Y.-W. (2002). "On the elastic modulus of hybrid particle/short-fiber/polymer composites," Composites Part B: Engineering 33(4), 291-299. DOI: 10.1016/S1359-8368(02)00013-6

Garrote, G., Domínguez, H., and Parajó, J. C. (2001). "Study on the deacetylation of hemicelluloses during the hydrothermal processing of Eucalyptus wood," Holz als Roh-und Werkstoff 59(1), 53-59. DOI: 10.1007/s001070050473

Godard, F., Vincent, M., Agassant, J.-F., and Vergnes, B. (2009). "Rheological behavior and mechanical properties of sawdust/polyethylene composites," Journal of Applied Polymer Science 112(4), 2559-2566. DOI: 10.1002/app.29847

Guyard, A., Persello, J., Boisvert, J.-P., and Cabane, B. (2006). "Relationship between the polymer/silica interaction and properties of silica composite materials," $J$. Polymer Sci. Part B: Polymer Physics 44(7), 1134-1146. DOI: 10.1002/polb.20768

Han, Y. H., Han, S. O., Cho, D., and Kim, H.-I. (2008). "Dynamic mechanical properties of natural fiber/polymer biocomposites: The effect of fiber treatment with electron beam," Macromolecular Research 16(3), 253-260. DOI: 10.1007/BF03218861

Harper, D., and Wolcott, M. (2004). "Interaction between coupling agent and lubricants in wood-polypropylene composites," Composites Part A: Applied Science and Manufacturing 35(3), 385-394. DOI: 10.1016/j.compositesa.2003.09.018

Hemmasi, A. H., Ghasemi, I., Bazyar, B., and Samariha, A. (2013). "Studying the effect of size of bagasse and nanoclay particles on mechanical properties and morphology of bagasse flour/recycled polyethylene composites," BioResources 8(3), 3791-3801. DOI: 10.15376/biores.8.3.3791-3801

Jose, M. V., Dean, D., Tyner, J., Price, G., and Nyairo, E. (2007). "Polypropylene/carbon nanotube nanocomposite fibers: Process-morphology-property relationships," Journal of Applied Polymer Science 103(6), 3844-3850. DOI: 10.1002/app. 25475

Klyosov, A. A. (2007). Wood-Plastic Composites, John Wiley \& Sons, New York, NY.

Ku, H., Wang, H., Pattarachaiyakoop, N., and Trada, M. (2011). "A review on the tensile properties of natural fiber reinforced polymer composites," Composites Part B: Engineering 42(4), 856-873. DOI: 10.1016/j.compositesb.2011.01.010

Martin-Gallego, M., Verdejo, R., López-Manchado, M. A., and Sangermano, M. (2011). “Epoxy-graphene UV-cured nanocomposites," Polymer 52(21), 4664-4669. DOI: 10.1016/j.polymer.2011.08.039

Mendes, A. A., Cunha, A. M., and Bernardo, C. A. (2011). "Study of the degradation mechanisms of polyethylene during reprocessing," Polymer Degradation and Stability 96(6), 1125-1133. DOI: 10.1016/j.polymdegradstab.2011.02.015

Najafi, S. K. (2013). "Use of recycled plastics in wood plastic composites - A review," Waste Management 33(9), 1898-1905. DOI: 10.1016/j.wasman.2013.05.017

Parvinzadeh, M., Moradian, S., Rashidi, A., and Yazdanshenas, M.-E. (2010). "Surface characterization of polyethylene terephthalate/silica nanocomposites," Applied Surface Science 256(9), 2792-2802. DOI: 10.1016/j.apsusc.2009.11.030

Pinheiro, L. A., Chinelatto, M. A., and Canevarolo, S. V. (2004). "The role of chain scission and chain branching in high density polyethylene during thermo-mechanical degradation," Polymer Degradation and Stability 86(3), 445-453. DOI: 10.1016/j.polymdegradstab.2004.05.016

Rafiee, M. A., Rafiee, J., Wang, Z., Song, H., Yu, Z.-Z., and Koratkar, N. (2009). "Enhanced mechanical properties of nanocomposites at low graphene content," ACS 
Nano 3(12), 3884-3890. DOI: 10.1021/nn9010472

Ramos, V. D., da Costa, H. M., Soares, V. L. P., and Nascimento, R. S. V. (2005).

"Modification of epoxy resin: A comparison of different types of elastomer," Polymer

Testing 24(3), 387-394. DOI: 10.1016/j.polymertesting.2004.09.010

Rong, M. Z., Zhang, M. Q., Pan, S. L., Lehmann, B., and Friedrich, K. (2004). “Analysis of the interfacial interactions in polypropylene/silica nano composites," Polymer International 53(2), 176-183. DOI: 10.1002/pi.1307

Rowell, R. M. (2012). Handbook of Wood Chemistry and Wood Composites, CRC Press, Cleveland, $\mathrm{OH}$.

Selke, S. E., and Wichman, I. (2004). "Wood fiber/polyolefin composites," Composites Part A: Applied Sci. Manuf. 35(3), 321-326. DOI: 10.1016/j.compositesa.2003.09.010

Shahi, P., Behravesh, A. H., Daryabari, S. Y., and Lotfi, M. (2012). "Experimental investigation on reprocessing of extruded wood flour/HDPE composites," Polymer Composites 33(5), 753-763. DOI: 10.1002/pc.22201

Tian, X., Zhang, X., Liu, W., Zheng, J., Ruan, C., and Cui, P. (2006). "Preparation and properties of poly(ethylene terephthalate)/silica nanocomposites," Journal of Macromolecular Science, Part B: Physics 45(4), 507-513. DOI: $10.1080 / 00222340600769782$

$\mathrm{Wu}, \mathrm{C} ., \mathrm{Xu}, \mathrm{T}$., and Yang, W. (2005). "Synthesis and characterizations of novel, positively charged poly(methyl acrylate)- $\mathrm{SiO}_{2}$ nano composites," European Polymer Journal 41(8), 1901-1908. DOI: 10.1016/j.eurpolymj.2005.02.031

Xanthos, M. (2010). Functional Fillers for Plastics, John Wiley \& Sons, New York, NY.

$\mathrm{Xu}, \mathrm{X}$., Li, B., Lu, H., Zhang, Z., and Wang, H. (2008). "The effect of the interface structure of different surface-modified nano- $\mathrm{SiO}_{2}$ on the mechanical properties of nylon 66 composites," Journal of Applied Polymer Science 107(3), 2007-2014. DOI: 10.1002/app.27325

Zahavich, A. T. P., Latto, B., Takacs, E., and Vlachopoulos, J. (1997). "The effect of multiple extrusion passes during recycling of high density polyethylene," Advances in Polymer Technology 16(1), 11-24. DOI: 10.1002/(SICI)10982329(199721)16:1<11::AID-ADV2>3.0.CO;2-M

Yang, Y., and Gu, H. (2007). "Preparation and properties of deep dye fibers from poly(ethylene terephthalate) $/ \mathrm{SiO}_{2}$ nanocomposites by in situ polymerization," Journal of Applied Polymer Science 105(4), 2363-2369. DOI: 10.1002/app.23069

Zhang, M. Q., Rong, M. Z., Zhang, H. B., and Friedrich, K. (2003). "Mechanical properties of low nano-silica filled high density polyethylene composites," Polymer Engineering and Science 43(2), 490-500. DOI: 10.1002/pen.10040

Zhang, X., Tian, X., Zheng, J., Yao, X., Liu, W., Cui, P., and Li, Y. (2008). "Relationship between microstructure and tensile properties of PET/silica nano composite fibers," Journal of Macromolecular Science Part B: Physics 47(2), 368-377. DOI: 10.1080/00222340701849277

Article submitted: Aug. 14, 2020; Peer review completed: Nov. 7, 2020; Revised version received and accepted: March 22, 2021; Published: April 13, 2021.

DOI: 10.15376/biores.16.2.3871-3885 